\title{
Amo você Vaatelainaamo, mas algumas coisas podem melhorar: Análise de motivações, barreiras e facilitadores em serviço finlandês de compartilhamento de roupas
}

I love you Vaatelainaamo, but some things can be improved: Analysis of motivations, barriers and opportunities in a Finnish service for sharing clothes

\section{Rosana Aparecida Vasques}

Doutora pela Faculdade de Arquitetura e Urbanismo da Universidade de São Paulo ravasques@gmail.com

Maria Cecília Loschiavo dos Santos

Doutora - Professora Titular da FAU USP closchia@usp.br

\section{Mikko Koria}




\section{Amo você Vaatelainaamo, mas algumas coisas podem melhorar: Análise de motivações, barreiras e facilitadores em serviço finlandês de compartilhamento de roupas

\author{
I love you Vaatelainaamo, but some things can be improved: Analysis of motivations, \\ barriers and opportunities in a Finnish service for sharing clothes
}

Rosana Aparecida Vasques, Maria Cecília Loschiavo dos Santos e Mikko Koria

\section{Resumo}

Este artigo apresenta os resultados de pesquisa realizada com usuárias de um serviço finlandês para o compartilhamento de roupas (Vaatelainaamo), cujo objetivo foi compreender motivações, barreiras e oportunidades para a adoção de práticas de consumo na Economia do Compartilhamento. A pesquisa fundamenta-se sob o paradigma interpretativo e estudo fenomenológico enquanto método, utilizando-se de questionários abertos como técnica de coleta de dados. Dentre os resultados, podemos destacar que o fraco sentimento de copropriedade, o descuido no cuidado com as roupas e a indisponibilidade de produtos e do serviço são fatores que prejudicam a relação das usuárias com o mesmo. Por outro lado, as principais motivações para a adesão ao serviço são: a consciência ambiental, a valorização da produção local e a oferta de acesso a itens considerados caros, permitindo a possibilidade de experimentação, associada ao prazer de utilizar roupas diferentes com menor impacto ambiental. Assim, Vaatelainaamo oferta uma solução ambientalmente e economicamente benéfica para o estilo de vida das usuárias, promovendo o sentimento de pertencimento, que é o fator principal para elas amarem esse serviço, ainda que alguns aspectos possam ser melhorados.

Palavras- chave: Economia do Compartilhamento; Design de serviços; Sustentabilidade.

\begin{abstract}
This paper presents the results of research conducted with users of a Finnish service for sharing clothes (Vaatelainaamo), which aimed to understand motivations, barriers and opportunities for adoption of consumer practices in the Sharing Economy. The research is based on the interpretive paradigm and phenomenological study, using open questionnaires as data collection method. Among the results, we can point out that the weak sense of co-ownership, neglect in caring for the clothes and the unavailability of products and even the service are factors that damage the relationship of users with the service. On the other hand, the main motivations for becoming a member of this service are: environmental awareness appreciation of local production and the provision of access to considered expensive items, allowing the possibility of experimentation, associated with pleasure to use different clothes with less environmental impact. Thus, Vaatelainaamo offers an environmentally and economically beneficial solution to the users' lifestyle, promoting the feeling of belonging, which is the main factor for they love this service, although some aspects can be improved.
\end{abstract}

Keywords: Sharing Economy; Service

Design; Sustainability. 


\section{INTRODUÇÃ̃O}

Serviços voltados ao uso compartilhado ainda são pouco difundidos (Vezzoli et al., 2012) em relação à ampla gama de empresas cujos modelos de negócios pautam-se pela lógica do mercado de venda e promoção da posse ao invés do acesso, ainda que configurem soluções com grande potencial de reduzir o impacto ambiental, em função de um menor número de produtos produzidos (Manzini e Vezzoli, 2002), além de estarem associadas a potenciais melhorias em termos de coesão social, por meio da integração entre vizinhos, gerações, gêneros e culturas diferentes (Manzini, 2008; Vezzoli, 2008).

Nesse sentido, Vezzoli et al. (2012) argumentam que a difusão de Sistemas de Produtos + Serviços (PSS), nos quais o uso compartilhado se insere, ainda é muito limitada por se tratarem de inovações radicais que desafiam hábitos de consumo, estruturas organizacionais e regulatórias. Por sua vez, Piscicelli, Cooper e Fischer (2015) ressaltam que os valores individuais dos consumidores influenciam, ainda que parcialmente, a aceitação, adoção e difusão de práticas de consumo colaborativo, com base em dados de pesquisa sobre uma plataforma online que promove $\mathrm{o}$ compartilhamento de produtos na Inglaterra, no modelo peer-to-peer $(\mathrm{P} 2 \mathrm{P}$, isto é, entre pessoas).

Por outro lado, pesquisadores da Teoria da Cultura do Consumidor (Consumer Culture Theory - CCT), como Russel Belk, apontam a construção do self como elemento essencial para se compreender práticas de consumo e aquisição de bens (Belk, 1988) e, mais recentemente, o acesso a bens como uma nova estratégia na construção da identidade (Belk, 2013).

Desse modo, entende-se que a questão da insustentabilidade nos níveis de produção e consumo de produtos é, em essência, uma questão cultural e de mudança de comportamento, pautada principalmente por relações humanas e de apego com produtos e serviços que medeiam tais relações. Diante desse cenário, evidencia-se a necessidade de investigação de aspectos subjetivos, plenos de significados, que se relacionam ao 
compartilhamento de produtos, bem como a relevância de se identificar barreiras e facilitadores para a promoção do design voltado ao uso compartilhado.

Portanto, o objetivo desta pesquisa foi o de identificar possíveis motivações, barreiras e facilitadores presentes em práticas de compartilhamento mediadas por serviços, especificamente em relação ao produto "roupa", dada sua associação com práticas de hiperconsumo e rápido descarte presentes no consumo de moda.

O serviço Vaatelainaamo, apresentado neste artigo, foi analisado em profundidade a partir do olhar de suas usuárias, que relataram as motivações para participarem do mesmo e apontaram o que amam ou odeiam em seu uso, por meio de cartas direcionadas a essa empresa, que expõem quais aspectos (econômicos, sociais, ambientais, dentre outros) são percebidos como mais relevantes para a adoção de práticas de compartilhamento mediadas por serviços.

\section{MÉTODO DE PESQUISA}

A pesquisa fundamentou-se sob o paradigma interpretativo (Moreira e Caleffe, 2006), com abordagem predominantemente qualitativa e estudo fenomenológico (Creswell, 2014; Martins e Bicudo, 1989) enquanto método, tendo em vista que o objetivo principal da pesquisa de doutorado (Vasques, 2015), da qual este estudo faz parte, foi a compreensão de significados atribuídos ao uso compartilhado e suas implicações para o design de produtos e serviços a partir de reflexões e práticas de compartilhamento.

Especificamente com relação ao serviço Vaatelainaamo, optou-se por utilizar o questionário como técnica de coleta de dados com as usuárias, por permitir a resposta sem a presença da pesquisadora, reduzindo, assim a influência desta ${ }^{1}$. O questionário incluiu questões abertas sobre: a) motivações para uso do serviço; b) avaliação da experiência de uso do serviço; c) elaboração de uma "Carta de Amor e

\footnotetext{
${ }^{1}$ Os questionários foram distribuídos pessoalmente, para serem respondidos em casa, em versão impressa ou digital, com acesso por meio de um QR Code. No caso de a usuária ter optado pelo questionário impresso, a devolução foi realizada na semana seguinte, juntamente com a roupa retirada.
} 
Ódio" (Love \& Hate Letters); d) impacto da experiência de compartilhamento em outras práticas de consumo.

A técnica de coleta de dados denominada Love \& Hate (ou Love and Break up) Letters são cartas redigidas por usuários e direcionadas às empresas, produtos ou serviços, que revelam o que as pessoas valorizam ou esperam desses ou, ainda, qual o motivo para romperem esse relacionamento. Essa técnica foi criada em 2009 pela empresa de consultoria SmartDesign, para que usuários expressassem pensamentos e sentimentos em relação a produtos e serviços, em um formato que fosse familiar para os pesquisados (Martin e Hanington, 2012). Também foi utilizada por Mager et al. (2011), em pesquisa sobre produtos e serviços de telefonia, e por Gerber (2012) para avaliar a relação de usuários com produtos tecnológicos, revelando, em ambos os estudos, potenciais melhorias aplicáveis no redesign de produtos e serviços.

Assim, a técnica "Cartas de Amor e Ódio" foi adicionada ao questionário destinado às usuárias da Vaatelainaamo como meio de capturar e revelar sentimentos e emoções que se manifestam no relacionamento com o serviço. Dessa forma, foi possível analisar quais emoções emergem do fenômeno estudado, no sentido de ampliar o entendimento do que motiva a adoção ou rejeição de serviços voltados a práticas de compartilhamento.

A idade média das respondentes é de 29 anos, com idade máxima e mínima variando entre 25 e 34 anos, o que corresponde ao perfil geral do público da Vaatelainaamo. Em sua maioria, as respondentes são membros há pelo menos um ano, o que indica aceitação em relação ao serviço prestado.

\section{VAATELAINAAMO: BIBLIOTECA FINLANDESA DE MODA}

A moda geralmente é associada com consumo, luxo e insustentabilidade. Contudo, a palavra finlandesa Vaatelainaamo, que nomeia o serviço analisado, pode ser traduzida para o português como "biblioteca da moda", deixando claro que a posse, o apego e o descarte não são vias de mão única para a moda. Esse serviço finlandês foi criado em 2011, com o objetivo de evitar o hiperconsumo, explorando comportamentos sustentáveis por meio do empréstimo de roupas. Segundo Hertta Päivärinta (2011), 
cofundadora da Vaatelainaamo: "A mensagem é simples: a moda pode ser consumida ecologicamente, eticamente e socialmente".

A ideia do negócio surgiu a partir de práticas espontâneas de compartilhamento de roupas entre duas amigas, que encontraram um serviço similar em uma de suas viagens à cidade de Estocolmo, na Suécia. Katjia Meriläinen² (2013) esclareceu, em entrevista, que o hábito de emprestar roupas é muito popular na Suécia, onde várias empresas atuam no modelo de bibliotecas, emprestando peças de vestuário gratuitamente. Porém, a ausência de monetização desses serviços resulta em uma grande quantidade de membros inativos:

\begin{abstract}
Na Suécia, por exemplo, emprestar roupas é popular, mas as empresas de empréstimo estão, em sua maioria, trabalhando como bibliotecas e não realmente fazendo negócios. Algumas têm mesmo cooperado com bibliotecas reais e foram capazes de usar suas soluções técnicas, como Klädoteket em Malmö. Porque emprestar é gratuito, essas bibliotecas de vestuário geralmente têm uma grande quantidade de adesões, mas muitos deles são bastante inativos ${ }^{3}$.
\end{abstract}

Em entrevista, Jere Vilo ${ }^{4}$ explicou que o serviço funciona com base em diferentes tipos de associações e os membros podem emprestar roupas assinadas por cerca de 50 jovens designers finlandeses, que estão começando a carreira, ou de marcas famosas, que disponibilizam peças para a empresa, quase sempre exclusivas. Além disso, as usuárias do serviço também podem disponibilizar peças para que as demais utilizem.

Existem três planos de associação ofertados pela empresa:

- Basic: $160 € /$ semestre - permite emprestar duas peças por semana. Esse plano pode ser adquirido com desconto por estudantes ao custo de $110 € /$ semestre.

\footnotetext{
${ }^{2}$ Katjia Meriläinen trabalhou na criação da estratégia de marketing da empresa em 2013, como parte das atividades de seu mestrado na Aalto University - School of Business.

${ }^{3}$ Tradução do original, em inglês: In Sweden for example loaning clothes is popular, but loaning companies are mostly working like libraries, and not really doing business. Some of have even cooperated with real libraries and been able to use their technical solutions, like Klädoteket in Malmö. Because loaning is free of charge, these clothing libraries usually have a great amount of memberships, but many of them are quite inactive.
}

${ }^{4}$ Jere Vilo era estagiário na Vaatelainaamo no período em que a pesquisa foi realizada. 
- Gold: $260 € /$ semestre - permite emprestar até três peças, podendo permanecer até duas semanas com elas;

- Platinum: $460 € /$ semestre - permite emprestar de três a quatro peças por semana, sem limite de tempo específico para devolução.

Também é possível experimentar o serviço ao custo de $25 €$ por semana, que permite emprestar uma peça de roupa ou um acessório. Dessa forma, o serviço se diferencia dos tradicionais aluguéis de roupas sociais por oferecer variadas opções de associações que criam um vínculo entre a empresa e a usuária do serviço, bem como a possibilidade de experimentar o serviço antes de se associar e até mesmo disponibilizar peças próprias para serem emprestadas a outras pessoas.

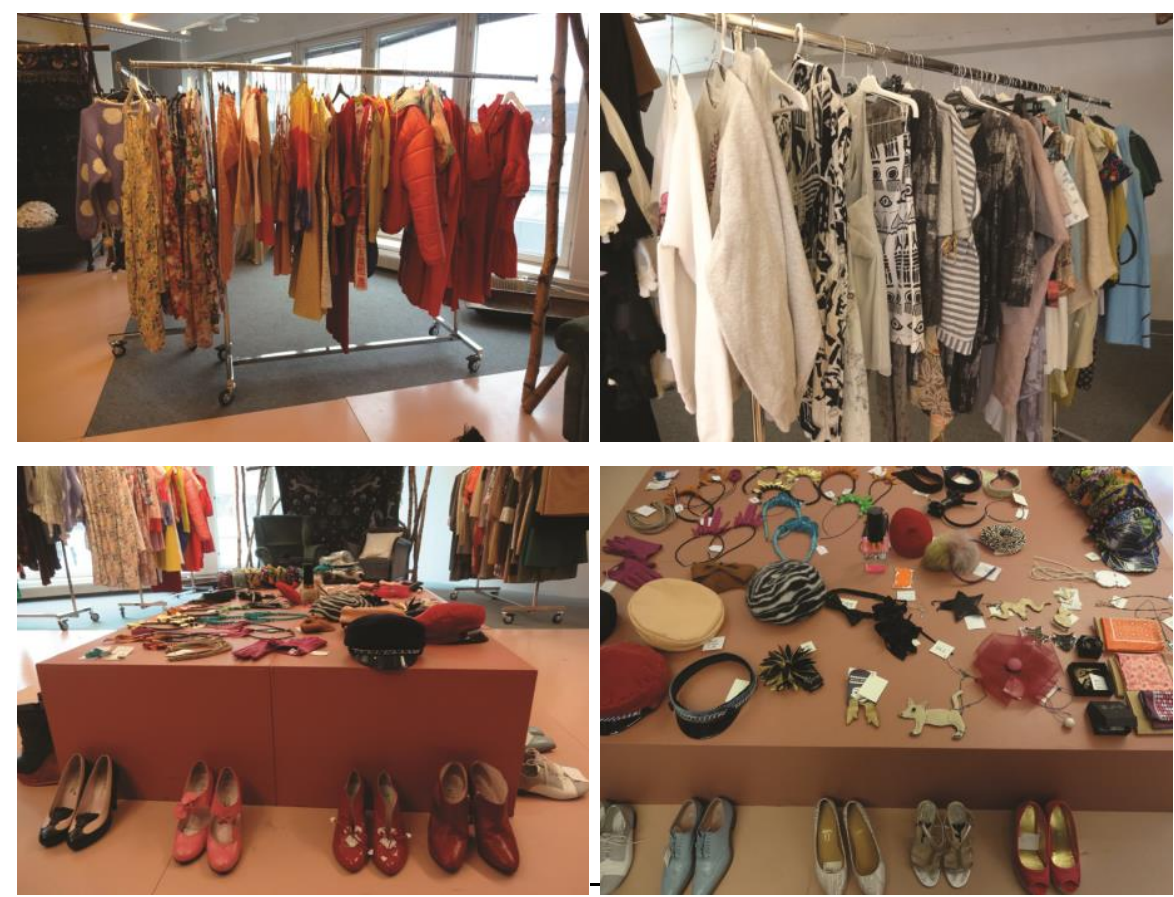

Figuras 1 a 4 - Produtos em exposição na Vaatelainaamo Fonte: Fotografias de Rosana A. Vasques, 2013

O serviço Vaatelainaamo possui cerca de 100 associadas, com faixa etária variando de 20 a 50 anos e a maioria entre 30 a 35 anos, que optam principalmente pelo plano Basic. Em 2013, o estoque chegava a quase mil peças, dentre roupas e acessórios cedidos ao projeto por designers em início de carreira ou por marcas famosas finlandesas e aquelas provenientes das próprias associadas (Meriläinen, 2013). 


\section{MOTIVAÇÕES, BARREIRAS E FACILITADORES: A VISÃO DAS USUÁRIAS DO SERVIÇO VAATELAINAAMO}

As roupas e acessórios são produtos altamente vinculados à identidade de quem os usa. A escolha do que vestir reflete, de forma incontestável, como uma pessoa deseja se apresentar aos demais; portanto, a indumentária é um produto essencial na construção do self. Assim, ao selecionarmos o serviço Vaatelainaamo como objeto de estudo para a compreensão de práticas de compartilhamento, as indagações exploratórias que se fizeram presentes foram:

- Qual a motivação para a desconstrução (ou reconstrução) desse aspecto da identidade, ao utilizar roupas que circularão por outros corpos e ajudarão outras pessoas a se definirem na semana seguinte?

- Por que a posse deixa de ser relevante para pessoas consideradas ávidas pelo consumo (fashionistas)?

- Por estar em contato com o corpo, que evoca questões sobre higiene e contaminação, a roupa seria um objeto com maiores barreiras para o compartilhamento?

- Como as usuárias se sentem em relação à higiene e o cuidado com as peças compartilhadas?

O aprofundamento da pesquisa, a partir da ótica das usuárias, permitiu-nos delinear algumas respostas para essas indagações exploratórias, que permearam o encaminhamento da pesquisa sem, contudo, defini-la, uma vez que, epistemologicamente, pautamo-nos pelo paradigma interpretativo e adotamos o estudo fenomenológico como método; portanto, não buscávamos a confirmação de hipóteses prévias, mas sim a investigação de experiências que potencialmente ampliariam o conhecimento sobre o recente fenômeno do compartilhamento mediado por serviços. As respostas das usuárias, dessa forma, apontaram motivações, dificuldades e facilitadores para a escolha desse serviço como prática de consumo de moda, conforme descrito nas seções a seguir. 


\title{
4.1 Consciência ambiental, experimentação e economia como impulsionadores do desapego em relação a roupas
}

Como principais motivações para utilizarem o serviço de compartilhamento de roupas e acessórios, as respondentes apontaram a economia de recursos financeiros, assim como a consciência ambiental e a preocupação com o hiperconsumo, teoricamente contraditórias para fashionistas. No entanto, o hiperconsumo encontra restrições financeiras, de espaço e ambiental, conforme registrado nas respostas das usuárias, que chancelam a escolha pelo acesso ao invés da posse:

\begin{abstract}
Eu queria comprar menos. Houve um momento no último ano em que eu percebi que não posso comprar todas as roupas bonitas que eu amo em função de: a. dinheiro e b. razões ecológicas. Desta forma, cada semana traz uma peça de roupa sem a prática esbanjadora de comprar até se afundar. ${ }^{5}$
\end{abstract}

Para evitar comprar mais roupas para mim mesmo e para poder vestir com maior frequência roupas e acessórios caros de designers sem possuí-los (Eu nem poderia me dar o luxo de comprá-los de qualquer maneira). ${ }^{6}$

Compartilhar coisas ao invés de comprar todas elas para você é uma opção ambientalmente amigável; diminui o consumo. ${ }^{7}$

Escolha ecológica e ética: Eu quero vestir roupas de designers finlandeses, mas eu odeio fazer compras e também é caro comprar tudo para si mesmo. ${ }^{8}$

Eu dei a eles algumas de minhas vestimentas e então eu automaticamente consegui a adesão, mas eu também queria começar a alugar outras vestimentas. ${ }^{9}$

Dessa forma, o acesso a roupas e acessórios (sapatos, bijuterias, bolsas, etc.) por uma pequena taxa, ao invés da posse por um preço considerado alto pelas respondentes, é percebido como benefício e conveniência superiores à exclusividade

\footnotetext{
${ }^{5}$ Do original, em inglês: I wanted to shop less. There was a point last year where I realized I can't buy all the beautiful clothes I love for a. monetary and b. ecological reasons. This way every week brings a new piece of clothing without the wasteful practice of shopping till you drop.

${ }^{6}$ Do original, em inglês: To avoid buying more clothes to myself and to be able to wear more frequently expensive designer clothes \& accessories without owning them (I couldn't even afford to buy them anyway).

${ }^{7}$ Do original, em inglês: Sharing things instead of buying them all for yourself is an environmentfriendly option, it lessens consumption.

${ }^{8}$ Do original, em inglês: Ecological and ethical choice: I want to wear Finnish designers clothes, but I hate shopping and it's also expensive to buy everything to yourself.

${ }^{9}$ Do original, em inglês: I gave them some of my garments and so I automatically got the membership, but I also wanted to start renting other garments as well.
} 
de uso. A possibilidade de experimentar novos estilos, sem o custo da posse, também foi indicada como um aspecto positivo, valorizado pelas usuárias:

Eu também queria ter novas ideias sobre o que vestir e para ter mais coragem de vestir uma roupa performática única que eu normalmente não vestiria ou compraria. ${ }^{10}$

Para experimentar meu estilo - Vestir "roupas novas" em cada evento que eu tenho (por meio do meu trabalho, eu tenho muitos eventos) - Então, poupar algum dinheiro, uma vez que eu não compraria tanto. ${ }^{11}$

O serviço atende, portanto, uma demanda específica, que transforma o encargo da posse no benefício da flexibilidade e da experimentação, característicos do público ao qual se destina.

Quanto à extensão do compartilhamento a outras práticas de consumo, para além da moda, menos da metade das respondentes relataram que participam de outros serviços voltados ao uso compartilhado ou de práticas de consumo colaborativo (troca, redistribuição e revenda). Contudo, é comum entre elas o compartilhamento e a troca em grupos de amigos, por meio de redes sociais como o Facebook.

As motivações para participar de serviços similares, que promovem o acesso ao invés da posse, corroboram os valores individuais que levam à adoção do serviço estudado, destacando-se a consciência ambiental e relacionada a práticas de hiperconsumo, além da necessidade de liberar espaços, e, de forma complementar, a facilidade promovida pelas redes sociais:

Eu gosto de compartilhar :-) e emprestar coisas ao invés de comprá-las. Já existem "coisas" suficientes neste mundo. Eu também não me importo em comprar itens antigos e de segunda mão. ${ }^{12}$

Às vezes eu tenho coisas extras e eu preciso me desfazer delas e, às vezes, eu posso precisar de algo e amigos, grupos do Facebook, são fáceis e rápidos. ${ }^{13}$

\footnotetext{
${ }^{10}$ Do original, em inglês: I also wanted to get new ideas on what to wear and to get more courage to wear unique "showstoppers" that I wouldn't normally wear or purchase.

${ }^{11}$ Do original, em inglês: To experiment my style - To dress "freshly" into every event that I have (through my work I have quite much events) - So spare some money as I wouldn't shop so much.

${ }^{12}$ Do original, em inglês: I like to share :-) and borrow things instead of buying them. There's enough "stuff" already in this world. I also don't mind buying old vintage \& second hand items.

${ }^{13}$ Do original, em inglês: Sometimes have extra stuff I need to get rid off and sometimes I might need something and friends, Facebook groups are easy and fast.
} 
Conforme o relato das participantes, a mudança de pensamento em relação às próprias práticas pautadas por aspectos de materialismo, possessividade e o medo do contato com estranhos também foram mitigados a partir da experiência de compartilhar, trocar e revender produtos pouco ou não mais utilizados.

\begin{abstract}
Sinto-me contente em não possuir, uma vez que eu tendo a ser muito protetor com as roupas que eu tenho, isto é, elas podem permanecer no armário e não em uso, o que é muito triste. Desta forma, talvez eu aprenda também a usar minhas próprias roupas, porque é para isso que elas foram feitas. ${ }^{14}$

Talvez eu tenha perdido o medo de entrar em contato com pessoas que eu não conheço depois de usar mais grupos do Facebook ou outros deste tipo para doar e conseguir coisas não desejadas, gratuitamente. Eu costumava ser um pouco temerosa em abrir nossa casa para estranhos $e$ ir sozinha para casas de pessoas que eu não conhecia antes, mas agora eu estou ficando um pouco mais tranquila sobre essas coisas. ${ }^{15}$
\end{abstract}

Por outro lado, valores individuais como desprendimento, generosidade, reciprocidade e ausência de materialismo também foram encontrados no discurso das participantes, mostrando que a adoção do serviço Vaatelainaamo ecoa em pessoas que previamente possuíam esses valores.

$$
\begin{aligned}
& \text { Eu também poderia emprestar minhas próprias roupas para a } \\
& \text { Vaatelainaamo. }
\end{aligned}
$$

Eu sempre pensei que quanto menos coisas você possui, melhor, então, minhas ideias sobre compartilhamento e posse não mudaram muito na verdade. ${ }^{17}$

A posse nunca foi importante para mim. ${ }^{18}$

Em síntese, as principais motivações para usar roupas de forma compartilhada por meio do serviço Vaatelainaamo são a consciência ambiental, a possibilidade de usar várias roupas diferentes todas as semanas e a economia de

\footnotetext{
${ }^{14}$ Do original, em inglês: I feel content with not owning; since I tend to be too protective of the clothes I own myself i.e. they might stay in the closet and not in use, which is very sad. This way maybe I'll learn to use also my own clothes, because that's what they were meant for.

${ }^{15}$ Do original, inglês: Maybe I lost the fear to contact people that I don't know after using more Facebook groups or such for giving and getting unwanted stuff for free. I used to be a bit scared to open our home for strangers and going alone for homes I didn't know before, but now I'm getting a bit more relaxed about these kind of things.

${ }^{16}$ Do original, em inglês: I could loan my own clothes as well to Vaatelainaamo.

${ }^{17}$ Do original, em inglês: I've always thought the less things you own the better, so my ideas regarding sharing \& ownership haven't really changed.

${ }^{18}$ Do original, em inglês: Ownership has never been important to me.
} 
recursos financeiros. Por outro lado, as barreiras identificadas para a adoção do compartilhamento são: o materialismo e a possessividade, além do medo do desconhecido, embora as respostas das usuárias sugiram que tais sentimentos se esmaeceram ao participarem da biblioteca da moda e de outros serviços que promovem o compartilhamento. Vale destacar, também, a preexistência de valores individuais em sintonia com os valores propostos pela Vaatelainaamo: generosidade e desprendimento associados ao consumo ético, social e ambientalmente responsável.

\title{
4.2 Amo você Vaatelainaamo, mas algumas coisas podem melhorar
}

Em sua maioria, as cartas foram iniciadas com declarações de amor e gratidão pela existência do serviço ou descrevendo o quanto as usuárias se sentem felizes por serem membros da Vaatelainaamo, demonstrando prazer no uso do serviço.

\begin{abstract}
Eu tenho curtido muito ser um membro, e aprecio você por fazer essa ideia uma realidade, embora eu tenha certeza que as pessoas possam ter sido céticas sobre o seu sucesso. Obrigado por dar visibilidade para designers finlandeses e roupas de qualidade. ${ }^{19}$
\end{abstract}

Obrigada por fazer este tipo de ação possível. Eu desejo energia para você, assim como acontecimentos positivos para o futuro! ${ }^{20}$

Muito obrigada; você está fazendo um ótimo trabalho! Mantenha! ${ }^{21}$

Até agora, eu estou muito feliz com esse serviço e o tenho recomendado a muitos amigos. As roupas que você empresta são lindas, e eu amo a ideia de compartilhar um guarda-roupa com outras pessoas. ${ }^{22}$

Eu amo a Vaatelainaamo, obviamente. E eu amaria ainda mais se houvessem novidades mais vezes! ${ }^{23}$

\footnotetext{
${ }^{19}$ Do original, em inglês: I have very much enjoyed being a member, and appreciate you for making this idea a reality, when I'm sure people might have been skeptical about its success. Thank you for giving visibility for Finnish designers and quality clothing.

${ }^{20}$ Do original, em inglês: Thank you for making this kind of action possible. I hope you energy and positive happenings for the future as well!

${ }^{21}$ Do original, em inglês: Thank you very much; you're doing a great job! Keep it up!

${ }^{22}$ Do original, em inglês: So far, I've been very happy with this service and I've recommended it to lots of friends. The clothes you lend out are beautiful, and I love the idea of sharing a wardrobe with other people.

${ }^{23}$ Do original, em inglês: I love Vaatelainaamo, of course. And I would love it even more, if there would be more new bees more often!
} 
A variabilidade e qualidade das roupas, associadas ao bom atendimento ao consumidor, também foram elogiadas em uma das cartas, ressaltando que apesar de alguns inconvenientes, o serviço, em termos gerais, promove satisfação entre as associadas:

Na Vaatelainaamo, eu amo a grande quantidade de diferentes itens e a qualidade das roupas, peças de designers e acessórios. O serviço ao consumidor é sempre muito simpático! ${ }^{24}$

A consciência ambiental descrita de forma breve nas motivações para compartilhar roupas por meio da Vaatelainaamo foram mais detalhadas nas cartas, bem como a existência de um pensamento crítico das associadas em relação à cultura do descarte e ao materialismo.

Um pequeno ponto negativo para um vestido "Monki" visto no rack. Para mim, ele representa uma cultura de descarte, sendo propriedade da H\&M. Mas se, e quando ele é de segunda mão, então pode ser perdoado. ;) ${ }^{25}$

A Vaatelainaamo é particularmente boa para empréstimos de vestidos extravagantes e outras roupas que você só poderia usar uma ou duas vezes. Não há nenhuma justificativa para possuir roupas assim. ${ }^{26}$

As cartas revelaram também algumas barreiras que podem prejudicar a aceitação ou mesmo a continuidade do uso do serviço, dentre elas destacam-se a ausência de cuidado com as roupas por outras usuárias em decorrência da falta de sentimento de copropriedade, a indisponibilidade de algumas peças e a incerteza de encontrar determinados modelos e/ou tamanhos.

O que eu não gosto muito é que alguns clientes não têm cuidado com as roupas como eu tenho. Às vezes eu tenho recebido roupas sujas, manchadas, e algumas vezes até mesmo estragadas (furos, dilacerações). Isso realmente me irrita. ${ }^{27}$

Eu também, por vezes, gostaria de reservar um vestido para mim para ocasiões especiais (festas de casamento, aniversários, festas importantes no

\footnotetext{
${ }^{24}$ Do original, em inglês: In Vaatelainaamo I love large amount of different items and the quality of clothes, designer pieces \& accessories. Customer service is always so friendly!

${ }^{25}$ Do original, em inglês: A teeny tiny minus for a Monki dress seen on the rack. For me it represents a culture of disposability being owned by H\&M. But if and when it's second hand, it may be forgiven. ;)

${ }^{26}$ Do original, em inglês: Vaatelainaamo is particularly good for borrowing fancy dresses and other outfits you might only use once or twice. There's no point in owning clothes like that.

${ }^{27}$ Do original, em inglês: What I don't like that much is that some other customers don't take care of the clothes as I do. Sometimes I have received dirty, stained clothes and few times even broken (holes, tearings). This really pisses me off.
} 
trabalho etc.), mas isso não é possível. Por isso, muitas vezes eu não gosto da ideia de ir até a Vaatelainaamo e não encontrar nada adequado para a ocasião e eu sou obrigado a comprar algo em outro lugar. A incerteza de saber se eu vou ser capaz de pegar emprestado da Vaatelainaamo ou não é irritante. Eu poderia pagar um pouco mais, se isso fosse possível. ${ }^{28}$

O valor pago para associação ao serviço não foi relatado como problema pelas participantes e mesmo a única queixa com relação a esse custo foi justificada por questões pessoais e possivelmente temporárias. A mensagem na carta deixa claro que a intenção da respondente é voltar a fazer parte da Vaatelainaamo, uma vez que sua experiência foi "extremamente positiva" com o serviço.

Infelizmente, ainda que minha experiência geral com a Vaatelainaamo seja extremamente positiva, já não posso me dar ao luxo de usá-la devido a minha situação financeira atual... Talvez novamente, no futuro! ${ }^{29}$

Por fim, o horário de atendimento foi apontado como um dos problemas da oferta, uma vez que estava limitado ao período entre 14 e $17 \mathrm{~h}$, somente na quinta e sexta-feira, o que limitava o horário para escolher e devolver as peças.

Eu apreciaria se a Vaatelainaamo estivesse aberta para além das $17 \mathrm{~h}$, pelo menos um dia da semana, uma vez que, para mim, é um pouco difícil deixar o trabalho antes das $17 \mathrm{~h}^{30}$

Esse problema foi resolvido com a mudança de endereço da empresa em setembro de 2013, quando as portas da biblioteca finlandesa da moda passaram a estar abertas das 14 às 19h, entre quarta e sexta-feira, como resposta às requisições das usuárias.

\footnotetext{
${ }^{28}$ Do original, em inglês: I would also sometimes like to reserve a dress of an outfit for me for special occasions (wedding parties, birthdays, important festivities at work etc.) but this is not possible.

Therefore I often don't like the idea of coming to Vaatelainaamo and finding nothing suitable for the occasion and I'm forced to buy something elsewhere. The uncertainty of whether I'll be able to borrow it from Vaatelainaamo or not is annoying. I could pay a bit more if this was possible.

${ }^{29}$ Do original, em inglês: Unfortunately, even when my overall experience of Vaatelainaamo is extremely positive, I can no longer afford to use it due to my current financial situation... Maybe again in the future!

${ }^{30}$ Do original, em inglês: I would appreciate it if Vaatelainaamo was open beyond 5 pm at least one day of the week, since it's a bit difficult for me to leave work before 5 .
} 


\section{CONCLUSÕES}

Pesquisar motivações, barreiras e facilitadores em um serviço de compartilhamento de roupas permitiu identificar aspectos que podem ser melhorados nesta oferta e a reflexão sobre possibilidades de ampliar a adoção do uso de serviços que promovem o acesso ao invés da posse, proposta da Economia de Compartilhamento. Além disso, o aporte teórico da Teoria da Cultura do Consumidor (CCT), que traz o entendimento das motivações para consumir ou deixar de fazê-lo, compreendendo a aquisição de bens e o compartilhamento como meio para a construção da identidade dos consumidores, mostrou-se como "lente" fundamental para a leitura das práticas analisadas.

O uso de questionários abertos, principalmente a inclusão das "Cartas de Amor e Ódio", como técnica de pesquisa, revelou aspectos emocionais que traduzem as motivações para adoção da prática de compartilhamento de roupas, de forma espontânea, declaradas em frases de amor, gratidão e incentivo para que o serviço continue a ser ofertado.

Quanto aos aspectos percebidos como mais relevantes para a adoção dos serviços de compartilhamento, as usuárias da Vaatelainaamo deixam claro que um novo perfil de consumo de moda é possível e que a construção da identidade também pode se estabelecer por meio do acesso aos bens, ao transparecer os valores individuais de generosidade, desprendimento e de crítica ao hiperconsumo, ou mesmo criar identidades temporárias: posso vir a utilizar novamente esta roupa em outra semana, mas pode ser que não a encontre mais disponível porque alguém sempre a escolhe antes de mim. Por outro lado, posso experimentar ser outra pessoa, num processo de maior liquidez na construção da própria identidade, por um menor custo financeiro e sem o encargo do estoque das peças.

Assim, pode-se afirmar que o apetite pelo novo, típico das práticas de hiperconsumo de fashionistas, ganha outra dimensão por meio da Vaatelainaamo: a consciência de que não é necessário (e por vezes nem possível) ter para ser, associada à preocupação ambiental e pensamento crítico com relação à cultura do descarte, talvez 
por influência, também, do contexto sociocultural finlandês, onde a natureza e as práticas sustentáveis têm um papel relevante.

No entanto, por ser um serviço de compartilhamento mediado por uma empresa, em que o contato com outras pessoas não é mandatório, a interação social não é sequer citada pelas respondentes, corroborando Belk (2010; 2013) e Barthi e Echkard (2012) em relação às motivações mais voltadas aos interesses individuais em práticas de compartilhamento que envolvem o uso de recursos financeiros.

Ainda assim, a análise das respostas das usuárias do serviço Vaatelainaamo sugere alterações no comportamento do consumidor em relação às posses, com maior abertura para o desapego e a valorização da característica "anticonsumo" da oferta.

Quanto ao impacto do uso do serviço nas práticas de consumo das usuárias, percebe-se a existência de uma via de mão dupla: tanto a experiência de consumo por meio da Vaatelainaamo torna as pessoas mais abertas à adoção de práticas sustentáveis de consumo como a escolha por participar desse serviço se fundamenta em valores preexistentes de generosidade, menor valorização das posses e de repúdio à cultura do descarte.

A adequação do preço, incluindo diversos tipos de associação e até mesmo uma opção para estudantes, integrada com o benefício da experimentação e uso de roupas de qualidade e de incentivo à produção local fomentam a possibilidade de crescimento dessa oferta. Por outro lado, o atendimento em horário e dias da semana limitados, além da ausência do senso de copropriedade em algumas das usuárias pode retrair as suas participações.

Contudo, a pesquisa revelou, notadamente a partir das "Cartas de Amor e Ódio", forte sentimento de pertencimento (Belk, 2007; 2010; Ozzane e Ballantine, 2010) ao serviço, identificado por meio dos agradecimentos e declarações de amor à Vaatelainaamo, por oferecer uma experiência "extremamente positiva", conforme declarado por uma das respondentes. Assim, o pertencimento é considerado fundamental para o desenvolvimento de outros produtos e serviços voltados ao compartilhamento, uma vez que pertencer a um grupo - ou "tribo" -, cujos valores são 
compartilhados, é, também, uma forma de construir o self, ao invés de unicamente por meio da posse.

\section{AGRADECIMENTOS}

Os autores agradecem às agências de fomento brasileiras CNPq e CAPES, que financiaram esta pesquisa (Processos: 143155/2011-3 e 18925-12-0, respectivamente), assim como ao Programa de Pós-Graduação da Faculdade de Arquitetura e Urbanismo da Universidade de São Paulo (FAU USP) e ao International Design Business Management Program, da School of Business - Aalto University, Finlândia, no qual o estágio de doutorado sanduíche foi realizado.

\section{Artigo recebido em Outubro de 2016. Aprovado em Novembro de 2016 DOI:http://dx.doi.org/105965/1982615x10192016023}

\section{REFERÊNCIAS}

BARDHI, F.; ECKHARDT, G. Access-based consumption. The case of car sharing. Journal of Consumer Research, vol.39, n.4, Dez, 2012, p. 881-898.

BELK, R. W. Possessions and the extended self. Journal of Consumer Research, vol.15, n.2. Set, 1988, p. 139-168.

. Why not share rather than own? The ANNALS of the American Academy of Political and Social Science, v.611, n.1, Maio, 2007, p. 126-140.

Sharing. Journal of Consumer Research, vol.36, n.5, Fev, 2010, p. 715-734.

. Extended self in a digital world. Journal of Consumer Research, vol.40, n.3, Out, 2013, p. 477-500.

CRESWELL, J. W. Investigação qualitativa e projeto de pesquisa: escolhendo entre cinco abordagens. Trad. Sandra Mallmann da Rosa. 3. ed. Porto Alegre: Editora Penso, 2014.

GERBER, E. Tech break ups: a research method for understanding people's attachment to their technology. Interactions. v. 9, n.5, Set-Out, 2012. p. 26-30.

MAGER, B. et al. E-frust. Köln: KISD, 2011. 
MANZINI, E. Design para a inovação social e sustentabilidade: comunidades criativas, organizações colaborativas e novas redes projetuais. Rio de Janeiro: Epapers, 2008.

MANZINI, E.; VEZZOLI, C. O desenvolvimento de produtos sustentáveis: os requisitos ambientais dos produtos industriais. São Paulo: EDUSP, 2002.

MARTIN, B.; HANINGTON, B. Universal Methods of Design: 100 ways to research complex problems, develop innovative ideas, and design effective solutions. Beverly: Rockport Publishers, 2012.

MARTINS J; BICUDO, M. A. V. A pesquisa qualitativa em psicologia: fundamentos e recursos básicos. São Paulo: Moraes, 1989.

MERILÄINEN, K. Entrevista concedida a Rosana A. Vasques em 27/6/2013.

MOREIRA, H.; CALEFFE, L. G. Metodologia da pesquisa para o professor pesquisador. Rio de Janeiro: DP\&A, 2006.

OZANNE, L. K.; BALLANTINE, P. W. Sharing as a form of anti-consumption? An examination of toy library users. Journal of Consumer Behaviour, vol. 9, 2010, p. 485498.

PÄIVÄRINTA, H. Nopsa launched a fashion library. Nopsa travels, 2011. Disponível em: http://www.nopsatravels.com/en/nopsa-launched-a-fashion-library/. Acesso em 5/6/2013.

PSICICELLI, L.; COOPER, T.; FISCHER, T. The role of values in collaborative consumption: insights from a product-service system for lending and borrowing in the UK. Journal of Cleaner Production, vol. 97, Jun, 2015, p. 21-29.

VEZZOLI, C. System design for sustainability: theory, methods and tools for a sustainable "satisfaction-system” design. Milano: Maggiori Editori, 2008.

VEZZOLI, C. et al. Why have 'Sustainable Product-Service Systems' not been widely implemented? Meeting new design challenges to achieve societal sustainability. Journal of Cleaner Production, 2012, p. 1-3.

VASQUES, R. A. Design, Posse e Uso Compartilhado: reflexões e práticas. 2015. Tese (Doutorado em Design e Arquitetura) - Programa de Pós-Graduação em Arquitetura e Urbanismo, Universidade de São Paulo, São Paulo.

VILO, J. Entrevista concedida a Rosana A. Vasques em 14/6/2013. 